\title{
Rendimento, composição química, benzo(a)pireno, microbiologia e sensorial de bandas de pacu defumadas com e sem pele
}

\author{
Yield, chemical composition, benzo(a)pyrene, microbiology and sensory of smoked pacu bands with \\ and without skin
}

Rendimiento, composición química, benzo (a) pireno, microbiología y sensorial de bandas de pacu

ahumado con y sin piel

Recebido: 11/12/2021 | Revisado: 16/12/2021 | Aceito: 21/12/2021 | Publicado: 04/01/2022

\author{
Adriana Ferreira da Silva \\ ORCID: https://orcid.org/0000-0002-6615-7938 \\ Universidad Autónoma de Yucatán, Mexico \\ E-mail; adriana.dasilva@correo.uady.mx \\ Gislaine Gonçalves Oliviera \\ ORCID: https://orcid.org/0000-0002-7819-3493 \\ Universidade Estadual de Maringá, Brasil \\ E-mail: gislaine_oliveira14@hotmail.com \\ Vitoria Regina Takeuchi Fernandes \\ ORCID: https://orcid.org/0000-0002-0021-5031 \\ Secretaria da Educação e do Esporte do Paraná, Brasil \\ E-mail: vrtfernandes@gmail.com \\ Fabricio Vieira dos Santos \\ ORCID: https://orcid.org/0000-0002-1242-8181 \\ Universidade Estadual de Maringá, Brasil \\ E-mail: fabriciovieiradsantos@gmail.com \\ Marcos Antonio Matiucci \\ ORCID: https://orcid.org/0000-0003-2053-2672 \\ Universidade Estadual de Maringá, Brasil \\ E-mail: m.matiucci@hotmail.com \\ Andresa Carla Feihrmann \\ ORCID: https://orcid.org/0000-0003-2389-0467 \\ Universidade Estadual de Maringá, Brasil \\ E-mail: andresafeihrmann@gmail.com \\ Nilton Marengoni \\ ORCID: https://orcid.org/0000-0002-0666-4567 \\ Universidade Estadual do Oeste do Paraná, Brasil \\ E-mail: nilton.marengoni@unioeste.br \\ Angélica de Souza Khatlab \\ ORCID: https://orcid.org/0000-0003-4823-4327 \\ Universidade Estadual de Maringá, Brasil \\ E-mail: angelicakhatlabuem@gmail.com \\ Josiane Aparecida Volpato \\ ORCID: https://orcid.org/0000-0002-6721-2388 \\ Universidade Estadual de Mringá, Brasil \\ E-mail: josyvolpato@yahoo.com.br \\ Thaís Pereira da Cruz \\ ORCID: https://orcid.org/0000-0002-2029-7011 \\ Universidade Estadual de Maringá, Brasil \\ E-mail:mmpcruz@hotmail.com \\ Maria Luiza Rodrigues de Souza \\ ORCID: https://orcid.org/0000-0001-5643-0841 \\ Universidade Estadual de Maringá, Brasil \\ E-mail: mlrsouza@uem.br
}

\begin{abstract}
Resumo
Analisou-se rendimento, composição química, benzo(a)pireno, microbiologia e sensorial e bandas de pacu (Piaractus mesopotamicus) defumado a quente com e sem pele. Foram utilizados 20 exemplares de pacu com peso médio de $2.754 \mathrm{~kg}$ e médio de cada banda 796,2 gramas. As bandas foram: lavadas, imersas em salmoura, drenadas e depois submetidas à defumação a quente. Não houve diferença significativa no peso defumado e nas perdas no processamento, mostrando que as amostras eram homogêneas. As bandas com pele $(48,39 \%)$ apresentaram um maior
\end{abstract}


rendimento de defumação, comparada as sem peles (44,91\%), enquanto as perdas foram de $13,79 \%$ e $21,78 \%$, respectivamente para as bandas com e sem pele. Houve redução do teor de umidade e consequentemente ocorreu a concentração dos demais nutrientes. A Proteína foi de $18,69 \%$ para $26,34 \%$ e 26,98\% e cinzas de $1,01 \%$ para $1,67 \%$ e $1,62 \%$, respectivamente para bandas de pacu com e sem pele, mostrando que só houve efeito da defumação. Enquanto, para lipídeos (15,52\% para $25,61 \%$ e $24,83 \%)$ e umidade $(65,15 \%$ para $44,36 \%$ e 40,95\%), além do efeito da defumação, a presença ou não da pele interferiu significativamente nesses nutrientes. Houve diferença significativa apenas para sabor, sendo as bandas sem pele consideradas mais saborosas. As bandas apresentaram baixos teores de benzo(a)pireno e houve redução dos coliformes a $35^{\circ} \mathrm{C}$ de $2,3 \times 101 \mathrm{NMP} / \mathrm{g}$ para $<3 \mathrm{NMP} / \mathrm{g}$, sendo recomendadas as bandas de pacu sem pele, apesar do menor rendimento no processo de defumação.

Palavras-chave: Características organolépticas; Defumação; Hidrocarbonetos policíclicos aromáticos.

\begin{abstract}
Yield, chemical composition, benzo(a)pyrene, microbiology and sensory and bands of hot smoked pacu (Piaractus mesopotamicus) with and without skin were analyzed. Twenty pacu specimens with an average weight of $2,754 \mathrm{~kg}$ and an average of 796.2 grams of each band were used. The bands were: washed, immersed in brine, drained and then subjected to hot smoking. There was no significant difference in smoked weight and processing losses, showing that the samples were homogeneous. The bands with skin $(48.39 \%)$ had a higher smoking yield compared to those without skin $(44.91 \%$ ), while the losses were $13.79 \%$ and $21.78 \%$, respectively for the bands with and without skin. There was a reduction in the moisture content and, consequently, the concentration of other nutrients occurred. Protein went from $18.69 \%$ to $26.34 \%$ and $26.98 \%$ and ashes from $1.01 \%$ to $1.67 \%$ and $1.62 \%$, respectively for pacu bands with and without skin, showing that there was only effect of smoking. While, for lipids (15.52\% to $25.61 \%$ and $24.83 \%$ ) and humidity $(65.15 \%$ to $44.36 \%$ and $40.95 \%)$, in addition to the effect of smoking, the presence or absence of skin significantly interfered with these nutrients. There was a significant difference only for flavor, with the skinless bands considered tastier. The bands had low levels of benzo(a)pyrene and there was a reduction of coliforms at $35^{\circ} \mathrm{C}$ from $2.3 \times 101 \mathrm{NMP} / \mathrm{g}$ to $<3 \mathrm{NMP} / \mathrm{g}$, with skinless pacu bands being recommended, despite the lower yield in the smoking process.
\end{abstract}

Keywords: Organoleptic characteristics; Smoking; Polycyclic aromatic hydrocarbons.

\title{
Resumen
}

Se analizaron rendimiento, composición química, benzo (a) pireno, microbiología y sensorial y bandas de pacu ahumado en caliente (Piaractus mesopotamicus) con y sin piel. Se utilizaron veinte ejemplares de pacu con un peso promedio de $2.754 \mathrm{~kg}$ y un promedio de 796.2 gramos de cada banda. Las bandas fueron: lavadas, sumergidas en salmuera, escurridas y luego sometidas a ahumado en caliente. No hubo diferencia significativa en el peso ahumado y las pérdidas de procesamiento, lo que demuestra que las muestras eran homogéneas. Las bandas con piel (48,39\%) tuvieron un mayor rendimiento de fumado en comparación con las sin piel $(44,91 \%)$, mientras que las pérdidas fueron de $13,79 \%$ y $21,78 \%$, respectivamente para las bandas con y sin piel. Hubo una reducción en el contenido de humedad y, en consecuencia, se produjo la concentración de otros nutrientes. La proteína pasó de 18,69\% a 26,34\% y 26,98\% y las cenizas de $1,01 \%$ a $1,67 \%$ y $1,62 \%$, respectivamente para las bandas de pacu con y sin piel, mostrando que solo hubo efecto del tabaquismo. Mientras que, para los lípidos $(15,52 \%$ a $25,61 \%$ y $24,83 \%)$ y humedad $(65,15 \%$ a $44,36 \%$ y 40,95\%), además del efecto del tabaquismo, la presencia o ausencia de piel interfirió significativamente con estos nutrientes. Hubo una diferencia significativa solo en el sabor, y las bandas sin piel se consideraron más sabrosas. Las bandas tenían niveles bajos de benzo (a) pireno y hubo una reducción de coliformes a $35^{\circ} \mathrm{C}$ de $2.3 \times 101 \mathrm{NMP} /$ ga <3 NMP / g, siendo recomendadas las bandas de pacu sin piel, a pesar del menor rendimiento en el proceso de ahumado.

Palabras clave: Características organolépticas; Ahumado; Hidrocarburos aromáticos policíclicos.

\section{Introdução}

A piscicultura é uma ótima alternativa para produção de alimento de alta qualidade nutricional, principalmente devido à facilidade que muitas espécies de peixes têm para serem produzidos em cativeiro, como por exemplo, a tilápia do Nilo (Oreochromis niloticus), pacu (Piaractus mesopotamicus), carpas (Cyprinus carpio) entre outras, assim como a elaboração de produtos com a inclusão de CMS e farinhas de peixe (Filho et al., 2021; Souza et al., 2021a; Honorato et al.2014,). A primeira é uma espécie amplamente estudada e cultivada mundialmente. As espécies de carpas são cultivadas em algumas regiões do Brasil e em menor escala, mundial, comparada a tilápia. Todavia, o pacu é uma espécie nativa das águas brasileiras, encontrada nos rios da Bacia do Prata, pertence à família Characidae e subfamília Myleinae (Bombardelli et al., 2007).

O pacu (Piaractus mesopotamicus) é um peixe facilmente encontrado em pesque-pague devido ao seu alto valor comercial, adaptação à alimentação artificial, facilidade de obtenção de larvas através da reprodução induzida (Furuya, 2001) e 
possui boa aceitação pelo mercado consumidor. Os peixes "redondos" como o pacu (Piaractus mesopotamicus) e o tambaqui (Colossoma mesopotamicus), geralmente são comercializados vivos para os diversos tipos de pesqueiros, ou inteiros eviscerados nas peixarias ou supermercados (Macedo-Viegas \& Souza, 2004) e é consumido, principalmente assado, mas atualmente há opções de cortes comerciais como costelinhas, lombo, filé e bandas (espalmado sem cabeça). Estes cortes podem ser defumados, o que vai agregar valor ao produto final e fornecer boas características específicas (Nitz et al.,2019).

$\mathrm{O}$ pescado é um produto extremamente perecível devido à alta atividade de água, composição química, teores de gorduras insaturadas que oxidam facilmente, $\mathrm{pH}$ praticamente neutro e de fácil ação microbiana (Macedo-Viegas e Souza, 2004), por isso estudos são necessários para melhorar sua produção, processamento, logística e viabilidade mercadológica. O consumo de pescado no Brasil é de aproximadamente $3,95 \mathrm{~kg} / \mathrm{hab} / \mathrm{ano}$, está abaixo do mínimo recomendável pela OMS (Organização Mundial de Saúde) (12kg/hab) (FAO, 2018).

A defumação, embora seja uma antiga técnica de conservação, tem sido utilizada para melhorar a qualidade dos pescados, uma vez que provoca mudanças nos atributos sensoriais, características que tornam o produto mais atrativo para o consumidor, bem como a praticidade em seu uso, por ser um prato pronto quanto defumado a quente, necessitando apenas aquecê-lo do momento de consumi-lo. O processo de defumação consiste em submeter o alimento aos efeitos de gases e vapor da queima de partes de plantas, com o propósito de aumentar a capacidade de conservação e modificação adequada de textura, cor, aroma e sabor dos alimentos (Prändl et al., 1994).

O processo de defumação pode ser frio ou a quente. Nesta, os pescados são colocados na câmara de defumação para uma desidratação inicial, com temperatura entre 40 a $50^{\circ} \mathrm{C}$, por uma ou duas horas, para em seguida adicionar a fumaça e elevar a temperatura lentamente até que atinja $80-85^{\circ} \mathrm{C}$. Já a defumação a frio, a temperatura não pode ultrapassar $40^{\circ} \mathrm{C}$, sendo a faixa ideal de $25-35^{\circ} \mathrm{C}$, para que não cozinhe o pescado. O tempo de defumação vai depender do tipo de produto que se deseja e o produto obtido desse processamento tem baixo teor de umidade, em torno de $40 \%$ e conteúdo de sal variando em torno de 7-15\%. Os produtos defumados a quente apresentam menor prazo de validade e não precisam ser cozidos antes de serem consumidos, enquanto que os processados com defumação a frio devem ser cozidos antes de consumir. O prazo de validade dos produtos defumado a frio é maior devido à sua maior exposição à fumaça.

Todas as etapas do processo de defumação, desde a escolha da espécie, captura, abate, descamação, evisceração, escolha dos cortes, salmouragem, drenagem, secagem, defumação, acabamento, embalagem influenciam na qualidade e validade do produto final (Macedo-Viegas \& Souza, 2004). Vários trabalhos foram desenvolvimento, utilizando o processo de defumação (Pereira et al.,2021; Dias et al.,2018; Mendonça et al.,2020; Calixto et al.,2019). Assim como trabalhos com inclusão de peixes foram desenvolvidos para alimentação humana (Souza et al.,2021b; Souza et al.,2021c; Souza et al.,2021d; Goes et al.,2016; Verdi et al.,2020; Matiucci et al.,2020; Kimura et al.,2017).

Diante disso, o presente estudo teve como objetivo realizar um estudo qualitativo, de acordo com Pereira et al. (2018) e também verificar as características de composição química, benzo(a)pireno, sensorial, microbiológicas e rendimento das bandas de pacu (Piaractus mesopotamicus) defumadas a quente com e sem pele.

\section{Metodologia}

Foram comprados de pesque-pagues da região de Maringá 20 exemplares de pacu (Piaractus mesopotamicus), com peso médio de $2,754 \mathrm{~kg}$. O pesqueiro, usou a metodologia de abate por meio do choque térmico em caixas isotérmicas com gelo e água (1:1). Os peixes abatidos foram pesados em balança eletrônica de precisão de $0,1 \mathrm{~g}$, depois foram lavados, descamados, eviscerados, cortados em bandas (espalmado sem cabeça) com pele e sem pele. A pele foi removida com o auxílio de um alicate e as bandas foram lavadas novamente, identificadas e pesadas. O peso médio obtido das bandas foi de 796,2 gramas. Estas bandas foram para o Laboratório de Pescado na Fazenda Experimental de Iguatemi, pertencente a 
Universidade Estadual de Maringá.

\section{Processo de defumação das bandas de Pacu}

As bandas foram lavadas, imersas em salmoura 20\% (2:1) durante 30 minutos, lavadas novamente em água corrente para retirar o excesso de sal da superfície e drenadas por uma hora para remover a água superficial. As bandas foram submetidas à defumação a quente, em defumador de inox artesanal, com geração de fumaça fora da câmara de defumação. As bandas foram submetidas a secagem inicial a $50^{\circ} \mathrm{C}$ por uma hora e, posteriormente foi adicionada a fumaça por oito horas em temperatura de $60-70^{\circ} \mathrm{C}$, de acordo com a metodologia utilizada por Souza et al. (2020a).

O combustível utilizado para produzir a fumaça foi serragem de eucalipto rosa (Eucalyptus globulus) e, para manutenção da temperatura, foi utilizado o gás de cozinha de acordo com metodologia aplicada por Matiucci et al. (2021).

Ao término da defumação, as bandas foram retiradas do defumador para estabilização da temperatura com o ambiente, embalados a vácuo individualmente e armazenadas sob refrigeração $\left(7 \pm 2^{\circ} \mathrm{C}\right)$, até a realização das análises.

\section{Análise de rendimento e perdas com a defumação}

O rendimento das bandas com pele e sem pele foi calculado em relação ao peso total do exemplar [(Peso da banda defumada/peso do peixe inteiro) x 100]. Para as perdas de defumação foi calculado em relação as bandas in natura [(Peso da banda defumada/peso da banda in natura com ou sem pele) $\mathrm{x} 100]$.

\section{Análise de composição química}

$\mathrm{Na}$ determinação da composição centesimal os teores de umidade, cinzas e extrato etéreo foram padronizados de acordo com a metodologia da Association of Official Analytical Chemists (AOAC , 2020). Os teores de proteína bruta foram avaliados pelo método de semi-micro Kjeldahl (Silva E Queiroz, 2002). Os teores de carboidratos foram estimados utilizandose uma fórmula matemática que considera a soma dos valores de umidade, proteína, lipídeos e cinzas subtraídos de 100\% (Brasil, 2003). O valor calórico total foi obtido pela soma da multiplicação dos valores das médias de proteína, lipídios e carboidratos multiplicados pelos fatores 4,9 e 4, respectivamente (Souci et al., 2000).

\section{Análise de benzo(a)pireno}

Foram realizadas análise de benzo(a)pireno em bandas in natura e defumadas com e sem peles. As amostras foram submetidas à saponificação com KOH metanólico, extração líquido-líquido com ciclohexano e dimetilformamida-água (9:1, v/v) e limpeza em coluna cromatográfica de sílica gel. A determinação foi feita por cromatografia líquida de alta eficiência com detecção por fluorescência (HPLC). Foram separadas amostras de cada tratamento (in natura, com pele e sem pele), para formar um pool e analisadas em triplicata.

\section{Análise microbiológica}

Foram realizadas análises microbiológicas para o número mais provável (NMP) de coliformes a $35^{\circ} \mathrm{C}$ e $45{ }^{\circ} \mathrm{C}$, contagem de Staphylococcus coagulase positiva em UFC/grama e de Salmonella spp, de acordo com APHA (1992). O protocolo microbiológico seguiu os padrões recomendados pela Resolução RDC nº 12, de 2 de janeiro de 2001, da Agência Nacional de Vigilância Sanitária (Brasil, 2001).

\section{Análise sensorial}

Para a análise sensorial, foram fornecidas amostras ( \pm 20 gramas $)$ das bandas de pacu defumada com e sem pele a 50 
provadores que avaliaram as características organolépticas. As amostras foram embaladas com papel alumínio e identificadas com três números aleatórios. Acompanhando as amostras foi fornecida aos provadores uma ficha com escala hedônica de 9 pontos, tendo como extremos 1 (desgostei muitíssimo) e 9 (gostei muitíssimo) para avaliação dos atributos de aroma, sabor e aparência (Dutcosky, 2013) e um copo de água para limpeza das papilas e um biscoito de água e sal. Estes com o objetivo de serem consumidos entre uma amostra e outra.

\section{Delineamento estatístico}

As bandas de pacu defumadas foram distribuídas em delineamento inteiramente casualizado, com dois tratamentos (com pele e sem pele), 20 repetições, sendo cada banda defumada considerada uma unidade experimental. Os dados obtidos foram submetidos ao teste F. Para composição química foi incluído na análise a banda in natura, sendo analisado os dados pelo teste de Tukey a 5\% de probabilidade. As análises microbiológicas e benzo(a)pireno foram realizadas apenas para caracterização das bandas de pacu, não sendo aplicado análise estatística.

\section{Resultados e Discussão}

\section{Rendimentos e perdas no processamento}

Não houve diferença significativa no peso das bandas defumadas e nas perdas no processamento das bandas de pacu com ou sem pele, mostrando que as amostras eram homogêneas.

As bandas com pele $(48,39 \%)$ apresentaram significativamente um maior rendimento de defumação, comparada as sem peles $(44,91 \%)$, consequentemente, as perdas foram de $13,74 \%$ e $21,78 \%$, respectivamente para as bandas com pele e sem pele (Tabela 1). Isto se deve em função da pele proteger o filé, deixando-o mais úmido. Segundo Souza et al. (2005), a gordura também pode influenciar nas perdas durante o processo de defumação, pois peixes com maior teor, perdem menos água, e a presença da pele na banda, proporciona uma menor área de superfície disponível (sem a presença de pele) para a perda dessa água. A pele age como um bloqueador da água no processo de desidratação da banda de pacu. Portanto, a técnica de preparo da matéria prima ou forma de apresentação do produto (com e sem pele) influenciou na perda de água e gordura natural do peixe, sendo significativamente maior para o produto defumado sem pele (Tabela 1).

A perda de peso no processo de defumação, segundo Sigurgisladottir et al. (2000), pode variar de 10 a $25 \%$ no produto final. Os resultados obtidos neste trabalho (Tabela 1) corroboram com essas informações de Sigurgisladottir et al. (2000). Estes autores relatam que os fatores que influenciam nessa perda são a origem da matéria prima (in natura, resfriado ou congelado), as características desejadas do produto ao término do processo, assim como os parâmetros usados no processo de defumação, tais como o tempo, temperatura, circulação de ar dentro do defumador, fluxo de fumaça, umidade interna do defumador e do produto a ser defumado, entre outros. Cardinal et al. (2001), também afirmam que as perdas no processo de defumação dependem do processamento aplicada, sendo atribuído principalmente ao efeito do tamanho do peixe ou filé em relação direta como a composição química.

Tabela 1 - Valores médios de rendimento do processamento das bandas de pacu (Piaractus mesopotamicus) defumadas.

\begin{tabular}{ccccc}
\hline Tratamentos & $\begin{array}{c}\text { Peso Bandas } \\
\text { defumadas }\end{array}$ & $\begin{array}{c}\text { Rendimento } \\
\text { defumado/Peso } \\
\text { corporal }\end{array}$ & $\begin{array}{c}\text { Perdas na defumação } \\
\text { das bandas }\end{array}$ & $\begin{array}{c}\text { Perdas de } \\
\text { processamento e } \\
\text { defumação }\end{array}$ \\
\hline Com pele & $686,79 \pm 3,45$ & $48,39 \pm 2,34$ & $13,74 \pm 3,56$ & $51,61 \pm 3,35$ \\
Sem pele & $622,79 \pm 1,87$ & $44,91 \pm 1,22$ & $21,78 \pm 1,92$ & $55,09 \pm 2,33$ \\
\hline Teste F & $0,9^{\mathrm{ns}}$ & $2,54^{*}$ & $3,61^{*}$ & $2,54^{\mathrm{ns}}$ \\
\hline C.V. $(\%)$ & 19,33 & 8,73 & 26,53 & 7,64 \\
\hline
\end{tabular}

Média \pm desvio padrão Teste $\mathrm{F}$ com $5 \%$ de probabilidade. ns - não significativo $(\mathrm{P}>0,05)$; * significativo $(\mathrm{P}<0,05)$. Fonte: Autores. 


\section{Composição química das bandas de pacu in natura e defumadas}

O processo de defumação alterou a composição química das bandas, como pode ser observado na Tabela 2, com a redução do teor de umidade houve concentração dos demais nutrientes (Tabela 2). A redução do teor de umidade variou de 20,79\% a 24,2\% em função da presença ou não da pele $n$ abanda de pacu. No entanto, com essa redução houve um acréscimo significativo no teor de proteína de $18,69 \%$ para $26,34 \%$ a $26,98 \%$, apesar dessa diferença não ter sido em função da presença ou não da pele na banda de pacu. Já para o teor de lipídeos houve um acréscimo em função da perda de umidade e associado a presença ou não da pele. As bandas sem pele $(24,83 \%)$, perderam mais lipídeos por desidratação e lixiviação no processo de defumação, comparado as com pele (25,61\%). Quanto aos teores de cinzas, houve acréscimo com o processo de defumação, associado a presença da adição de cloreto de sódio, porém a presença ou não da pele não influenciou nesses valores (Tabela 2).

Tabela 2 - Composição química das bandas de pacu in natura e defumadas (com e sem pele).

\begin{tabular}{|c|c|c|c|c|c|}
\hline \multirow{2}{*}{ Nutrientes (\%) } & \multirow{2}{*}{ In natura } & \multicolumn{2}{|c|}{ Defumados } & \multirow{2}{*}{ Valor de $\mathrm{P}$} & \multirow[b]{2}{*}{ C.V.(\%) } \\
\hline & & Com Pele & Sem Pele & & \\
\hline Umidade & $65,15 \pm 3,52 \mathrm{a}$ & $44,36 \pm 3,50 b$ & $40,95 \pm 2,11 \mathrm{c}$ & $<0,0001$ & 21,30 \\
\hline Proteína Bruta & $18,69 \pm 2,33 b$ & $26,34 \pm 2,40 \mathrm{a}$ & $26,98 \pm 2,10 \mathrm{a}$ & $<0,0001$ & 17,32 \\
\hline Lipídeos & $15,52 \pm 1,67 \mathrm{c}$ & $25,61 \pm 0,22 \mathrm{a}$ & $24,83 \pm 1,01 b$ & $<0,0001$ & 19,37 \\
\hline Cinzas & $1,01 \pm 0,14 \mathrm{~b}$ & $1,67 \pm 0,49 \mathrm{a}$ & $1,62 \pm 0,45 \mathrm{a}$ & $<0,0001$ & 2,45 \\
\hline
\end{tabular}

Média \pm desvio padrão seguido pelas letras minúsculas distintas diferem significativa pelo teste de Tukey a 5\%. Fonte: Autores.

Franco et al. (2010) avaliaram filés de matrinxã defumados pelo método a quente e a frio. Os autores relataram que o método influenciou na composição química dos filés, ocorrendo uma redução no teor de umidade e consequentemente uma concentração dos demais nutrientes. A redução de umidade, segundo os autores foi de $72,91 \%$ para $58,51 \%$ a $59,68 \%$, sendo que o método a quente ou a frio não influenciou nessa redução e sim apenas o fato de serem defumados, independentemente do método aplicado. Por outro lado, afirmaram que houve uma concentração no teor de cinzas (de 1,25\% para 3,28 a 3,47\%) e lipídeos (de 3,37\% para 7,76 a 8,09\%), devido à redução de umidade e inclusão de cloreto de sódio no processamento para o teor de cinzas. Para lipídeos, o método a quente $(8,09 \%)$ ou a frio $(7,76 \%)$ não influenciou na concentração desse nutriente. O mesmo ocorreu neste experimento com as bandas de pacu. Já, para o teor de proteína (in natura=20,07\%), o acréscimo deste nutriente, de acordo com Franco et al. (2010), deve-se a perda de água no processo e o método aplicado de defumação, sendo que no a quente apresentou maior teor $(28,07 \%)$ em relação ao a frio $(27,14 \%)$.

O teor de gordura é muito importante para o processo de defumação, sendo considerados os peixes com maior teor de gordura (acima de 10\% de lipídios) como os mais indicados, pois Huda et al. (201) afirmam que essa gordura do pescado atua como absorvedor das substâncias aromáticas presentes na fumaça, proporcionando maior aroma e sabor no produto defumado. Além de contribuir na cor devido à lixiviação da gordura no processo de defumação, dando um aspecto mais brilho na superfície desse defumado. Mas, o teor de umidade no peixe defumado também é de grande importância na qualidade organoléptica, pois à medida que diminui a umidade, o produto vai ficando com consistência mais seca e dura, diminuindo consequentemente a aceitabilidade do produto. No entanto, no processo de defumação deve ocorrer a perda de água sendo desejado que seja em torno de 60 a $65 \%$ (Macedo-Viegas e Souza, 2004).

Segundo Souza et al. (2005) dependendo da espécie de peixe não é possível defumá-la sem a pele, principalmente aquela com maior teor de lipídios como o pacu (Piaractus mesopotamicus), pois Andersen et al. (1997) afirmaram que elevados teores de lipídios proporcionam menor resistência dos filés ao trauma mecânico. Estudos com diferentes espécies de peixes, diferentes teores de lipídios e cortes diferenciados devem ser realizados para verificar a viabilidade mercadológica e 
aceitação por parte dos consumidores.

Esse trabalho demonstrou que há a possibilidade de defumar peixes com teores de lipídios mais elevados, na forma de bandas sem a pele, sem que haja quebras nessas bandas de pacu, e que os mesmos são considerados saborosos. Para tanto, as bandas foram dispostas no sentido horizontal dentro de defumador, sobre telas metálicas de inox. Também, no processo de defumação se bem executado, no passo a passo, onde deve-se deixar reduzir a umidade da superfície e depois utilizar baixas temperaturas para a formação da película sobre a superfície do produto a ser defumado, juntamente com os compostos da fumaça isto servirá para dar maior resistência evitando que o mesmo se dependurado, caia no defumador. Souza et al. (2020) observaram através da microscopia eletrônica de varredura a película envolvendo os filés que se forma no processo de defumação. Os autores mencionam que é muito importante em filés sem peles defumados a quente, a formação da película, para dar uma estrutura de maior consistência para evitar que os filés se rompam ao toque ou leve pressão.

\section{Análise de Benzo(a) pireno}

O processo de defumação interferiu no teor de benzo(a)pireno nos filés in natura em relação aos defumados com e sem peles. Os filés in natura apresentaram $0,23 \mu \mathrm{g} / \mathrm{kg}$ de benzo(a)pireno e com a defumação houve um aumento para 0,35 a $0,48 \mu \mathrm{g} / \mathrm{kg}$. A defumação, em função da temperatura utilizada proporcionou um aumento nos teores de benzo(a)pireno, sendo que as bandas sem peles apresentaram significativamente maior teor em relação aos demais. Talvez em função das maiores perdas de umidade facilitou a absorção dos compostos da fumaça na superfície da banda. Estas variações também, segundo Souza et al. (2020) dependem do maior tempo de exposição do produto aos compostos da fumaça em pirólise, assim como a temperatura de geração da fumaça que é outro fator importante, influenciando nos níveis de hidrocarbonetos policíclicos aromáticos (HPAs) na fumaça que tempo de exposição. Os mesmos autores relataram que filés de tilápia defumados pelo método a quente e a frio apresentaram teores de $0,49 \mu \mathrm{g} / \mathrm{kg}$ e $0,45 \mu \mathrm{g} / \mathrm{kg}$, respectivamente, enquanto que no in natura 0,26 $\mu \mathrm{g} / \mathrm{kg}$. Os teores relatados por Souza et al. (2020) foram superiores aos encontrados neste trabalho.

\section{Análise microbiológica}

Antes da defumação, as bandas de pacu apresentaram 2,3x101 NMP/g de coliformes a $35^{\circ} \mathrm{C},<3$ de coliformes a $45^{\circ} \mathrm{C},<1 \times 102 \mathrm{UFC} / \mathrm{g}$ na contagem de estafilococos e ausente em Salmonella spp. Após a defumação houve uma redução dos coliformes a $35^{\circ} \mathrm{C}(<3 \mathrm{NMP} / \mathrm{g})$, fato explicado porque a defumação exerce uma ação sobre a microflora dos produtos cárneos, pois os componentes da fumaça desenvolvem ação bactericida, proporcionando a inibição dos microrganismos por dessecação, e a defumação a quente proporciona destruição dos microrganismos por efeito de altas temperaturas (Prändl et al.,1994). Segundo a Resolução $n^{\circ}$ 12, de 02 de janeiro de 2001, da Agência Nacional de Vigilância Sanitária (ANVISA), o pescado defumado, pode apresentar até <102 UFC/g de coliformes totais e fecais e até 5x102 de Staphylococcus coagulase positiva/g. Portanto, os valores encontrados de microrganismos nas bandas de pacus com e sem pele, após a defumação estão dentro dos padrões microbiológicos para consumo (Brasil, 2001). Dessa forma, a temperatura da defumação é muito importante na redução desses microrganismos, juntamente com a ação dos bactericidas presentes na fumaça, conforme Bressan (2002). A duração do fluxo de fumaça aplicada ao processo também influencia na eliminação de microrganismos, pois de acordo com Franco et al. (2013), temperatura em torno de $40^{\circ} \mathrm{C}$ aplicada no processo de defumação a frio foi suficiente para eliminar Salmonella sp. presente nos filés in natura.

Portanto, pode-se afirmar que o processo de defumação, independente da temperatura utilizada é eficiente para reduzir ou eliminar microrganismos presentes no produto in natura. 


\section{Análise sensorial}

A análise sensorial (Tabela 3) demonstrou que entre as bandas com ou sem pele não houve diferença significativa para as características de aroma e aparência, mas para sabor, as bandas sem pele foram consideradas mais saborosas. Provavelmente pelo fato de as bandas estarem sem a pele, houve maior absorção dos compostos da fumaça numa maior área de superfície. Em relação à espécie, Ogawa (1999) relata que peixes com maior teor lipídico são mais saborosos.

Tabela 3 - Valores médios das notas atribuídas pelos provadores às características organolépticas das bandas de pacu (Piaractus mesopotamicus) com e sem pele defumadas.

\begin{tabular}{lccc}
\multicolumn{1}{c}{ Tratamentos } & Aroma & Sabor & Aparência \\
\hline Com pele & $7,56 \pm 1,31$ & $7,24 \pm 1,24$ & $7,32 \pm 1,33$ \\
Sem pele & $7,85 \pm 1,64$ & $8,73 \pm 1,98$ & $7,54 \pm 1,03$ \\
\hline Teste F & $0,01^{\text {ns }}$ & $2,06^{*}$ & $0,04^{\text {ns }}$ \\
\hline C.V. $(\%)$ & 8,6 & 7,29 & 9,69 \\
\hline
\end{tabular}

ns - não significativo $(\mathrm{P}>0,05)$; significativo $(\mathrm{P}<0,05)$. Fonte: Autores.

De acordo com Idah e Nwankwo (2013) nota 8,3 para o atributo sabor é considerada excelente, portanto, como houve diferença significativa apenas para este atributo e o valor obtida neste experimento foi de 8,73, acima do relatado pelos autores supracitados, pode-se inferir que a banda sem pele é a mais indicada para a produção.

Quanto ao índice de aceitabilidade foi superior a 70\% e de acordo com Dutcosky (2013) é considerado como um produto bem aceito pelos provadores. De acordo com Dutcosky (2013) a nota 8 é considerada como gostei muito, no entanto, a nota foi 8,7, estando muito mais próximo do considerado como gostei muitíssimo por essa escala dos nove pontos segundo Dutcosky (2013).

Em função dos resultados obtidos neste experimento, recomenda-se reduzir o tempo de defumação das bandas de pacu, independentemente de estarem com e sem pele, para que apresentem maior teor de umidade e consequentemente aumentando o rendimento do processo de defumação, devido às menores perdas de água da desidratação.

\section{Conclusão}

Bandas defumadas com pele proporciona maior rendimento de processamento, e menores perdas com a defumação, influenciando no teor de umidade e lipídeos, que foram maiores em relação as bandas sem pele. Com a redução de umidade houve concentração dos demais nutrientes, no entanto, apenas proteína e cinzas não foram influenciados pela presença ou não da pele nas bandas. As bandas sem pele foram consideradas as mais saborosas, sendo mais indicada essa forma de apresentação (sem pele) do produto para defumação. O processo de defumação proporciona a redução da carga microbiana, em função da temperatura e dos compostos da fumaça. Desta forma, mais trabalhos com defumação em peixes devem ser realizados para a maior inclusão desse processo na alimentação humana.

\section{Referência}

Aba, I. P., \& Ifannyi, N. (2013). Effects of smoke-drying temperatures and time on physical and nutritional quality parameters of Tilapia (Oreochromis niloticus). International journal of Fisheries and Aquaculture, 5(3), 29-34.

Andersen, U. B., Thomassen, M. S., \& Rørå, A. M. B. (1997). Texture properties of farmed rainbow trout (Oncorhynchus mykiss): effects of diet, muscle fat content and time of storage on ice. Journal of the Science of Food and Agriculture, 74(3), 347-353.

ANVISA (Agência Nacional de Vigilância Sanitária). Regulamento técnico sobre padrões de qualidade para alimentos. Resolução - RDC n. 12, de 02 de janeiro de 2001.

AOAC. Association Of Official Analytical Chemists-AOAC. (2005). Official methods of analyses of the association of analytical chemists. 
APHA - Americam Pubblic Health Association. (1992) Compendium of methods for the microbiological examination of foods. (3a ed.), 15 APHA.

Bombardelli, R. A. et al. Processamento da carne do pacu (Piaractus mesopotamicus) cultivado em tanques-rede no reservatório de Itaipu. Acta Sci. Animal Sciences, 29(4), 457-463, 2007.

Brasil. (2001). Ministério da Saúde. Agência Nacional de Vigilância Sanitária. Resolução RDC n. 12, de 02 de janeiro de 2001. Regulamento Técnico sobre os padrões microbiológicos para alimentos.

Brasil. (2003) Ministério da agricultura, pecuária e do abastecimento. Instrução normativa ${ }^{\circ} 62$

Calixto, F. A. A., Dias, G. E. A., Schmalz, K. R. P., Franco, R. M., Latini, J. T. P., \& Mesquita, E. F. M. (2019). Efeito do processamento de defumação na qualidade de bijupirá (Rachycentron canadum): atributos bacteriológicos, químicos e sensoriais. Arquivo Brasileiro de Medicina Veterinária e Zootecnia, 71 , 687-695.

Coradini, M. F., Cavicchioli, N., Chambo, A. P. S., \& Lucca, G. (2021) Inclusão de farinha de peixes de diferentes espécies em massa de esfirra aberta inclusion of fish flour of different species in open sphere pasta.Ciagro.Ciência tecnologia e inovação do campo a mesa.DOI :https://doi.org/10.31692/ICIAGRO.2020.0379

Dias, J. A. R., Abreu, A. S., Da Silveira, D. S., Arthur dos Santos, D. A., ABE, H. A., da Silva Gomes, J. L., \& Cordeiro, C. A. M. (2018). Uso de alecrim (Rosmarinus officinalis 1.) no processo de defumação de peixes continentais. Revista Brasileira de Engenharia de Pesca, 11(1), 55-68.

Dutcosky, S. D. (2011). Análise Sensorial de Alimentos. (3a ed.), Universitária Champagnat.

FAO. (2018). El estado mundialde la pesca y la aquicultura 2018. Cumplit los objetivos de desarrollo sostenible. Roma

Franco, M. L. R. D. S., Amaral, L. A. D., Viegas, E. M. M., Kronka, S. D. N., Gasparino, E., Mikcha, J. M. G., \& Del Vesco, A. P. (2013). Qualidade microbiológica e vida útil de filés defumados de tilápia-do-nilo sob refrigeração ou congelamento. Pesquisa Agropecuária Brasileira, $48,1071-1079$.

Franco, M. L. R. D. S., Viegas, E. M. M., Kronka, S. N., Vidotti, R. M., Assano, M., \& Gasparino, E. (2010). Effects of hot and cold smoking processes on organoleptic properties, yield and composition of matrinxa fillet. Revista Brasileira de Zootecnia, 39, 695-700.

Furuya, W. M. (2001) Espécies nativas. In: Moreira, H. L. M. et al. Fundamentos da Moderna Aqüicultura. ULBRA.

Goes, E. S. D. R., Souza, M. L. R. D., Michka, J. M. G., Kimura, K. S., Lara, J. A. F. D., Delbem, A. C. B., \& Gasparino, E. (2016). Fresh pasta enrichment with protein concentrate of tilapia: nutritional and sensory characteristics. Food Science and Technology, 36, 76-82.

Honorato, C. A., Caneppele, A., Matoso, J. C., Prado, M. R., Siqueira, M. S., \& Souza, L. R. O. (2014). Caracterização física de filés de Surubim (Pseudoplatystoma sp.), Pacu (Piaractus mesopotamicus) e Pirarucu (Arapaimas gigas). Arquivos de Ciências Veterinárias e Zoologia da UNIPAR, 17(4).

Huda, N., Alistair, T. L. J., Lim, H. W., \& Nopianti, R. (2012). Some quality characteristics of Malaysian commercial fish sausage. Pakistan Journal of Nutrition, 11(8), 700-705.

Kimura, K. S., de Souza, M. L. R., Verdi, R., Coradini, M. F., Mikcha, J. M. G., \& dos Reis Goes, E. S. (2017). < b> Nutritional, microbiological and sensorial characteristics of alfajor prepared with dehydrated mixture of salmon and tilapia. Acta Scientiarum. Technology, $39(1), 111-117$.

Macedo-Viegas, E. M., \& Souza, M. L. R. D. (2004). Pré-processamento e conservação do pescado produzido em piscicultura. Cyrino, Jep; Urbinati, Ec; Fracalossi, Dm, 217-238.

Matiucci, M. A., Chambó, A. P. S., de Souza Alves, L. F., Silva, A. A., Oliveira, G. G., Corrêa, S. S., \& de Souza, M. L. R. (2021). Ação antioxidante de pigmentos naturais em filés de tilápia do Nilo defumados. Research, Society and Development, 10(13), e79101320464-e79101320464.

Mendonça, W. C. B., Marcondes, A. S., de Souza, J. C. M., Ziemniczack, H. M., Sousa, R. M., \& Honorato, C. A. (2020). Defumação da traíra (Hoplias malabaricus) como método alternativo de conservação. RealizAção, 7(13), 53-61.

Nitz, L. F., Maltez, L. C., Pellegrin, L., de Oliveira Garcia, L., Barbas, L. A. L., \& Prentice-Hernández, C. (2019). Qualidade da carne e respostas de estresse em Piaractus mesopotamicus após exposição à níveis subletais de amônia e subsequente recuperação. Boletim do Instituto de Pesca, 45(1).

Ogawa, M., \& Maia, E. L. (1999). Química do pescado. Ogawa, M.; Maia, EL Manual de pesca: ciência e tecnologia do pescado. São Paulo: Varela, 1, 29-48.

Pereira, I. L., da Silva, D. D. S., Rocha, L. M. P., Oliveira, G. G., Coradini, M. F., Nogueira, C. C. A., ... \& de Souza, M. L. R. (2021). Comparação de linguiças defumadas elaboradas com aparas (corte em "V" do filé) de tilápia em relação as de carne de bovino, de suíno e de aves. Research, Society and Development, 10(11), e341101119728-e341101119728.

Pereira, A. S., Shitsuka, D. M., Parreira, F. J., \& Shitsuka, R. (2018). Metodologia da pesquisa científica. [e-book].

Prändl, O.; Fischer, A.; Schmidhofer, T; Sinell, H. J. (1994) Tecnologia e higiene de la carne. Zaragoza: Acribia.

Sigurgisladottir, S., Sigurdardottir, M. S., Torrissen, O., Vallet, J. L., \& Hafsteinsson, H. (2000). Effects of different salting and smoking processes on the microstructure, the texture and yield of Atlantic salmon (Salmo salar) fillets. Food Research International, 33(10),847-855

Souci, S. W., Fachmann, W., \& Kraut, H. (2000). Food composition and nutrition tables (No. Ed. 6). Medpharm GmbH Scientific Publishers.

Souza, M. L. R. (2021). Cereal matinal elaborado com inclusão de mix desidratado a partir de espinhaço de peixes. Ciência e Tecnologia de Alimentos: pesquisa e práticas contemporâneas.16 (1), 216-229.

Souza, M. L. R. et al. (2005). Efeito do peso de Tilápia do Nilo (Oreochromis niloticus) sobre o rendimento e a qualidade de seus filés defumados com e sem pele. Ciênc. Tecnol. Aliment., 25(1), 51-59. 
Research, Society and Development, v. 11, n. 1, e15111124630, 2022

(CC BY 4.0) | ISSN 2525-3409 | DOI: http://dx.doi.org/10.33448/rsd-v11i1.24630

Souza, M. L. R., Chambó, A. P. S., de Souza, H. B., Oliveira, G. G., Matiucci, M. A., Sbaraini, S. C., \& dos Reis Goes, E. S. (2021d ). Diferentes níveis de inclusão de farinha elaborada a partir de carcaças cozidas de tilápia do Nilo em pão caseiro. Research, Society and Development, 10(12), e389101220208e389101220208.

Souza, M. L. R., Souza, E. D., Matiucci, M. A., Feihrmann, A. C., Oliveira, G. G., Sbaraini, S. C., \& Goes, E. S. R. (2021a). Inclusão de toucinho em kaftas elaboradas com aparas de filés de tilápia: composição química, microbiológica e sensorial. Ciência e Tecnologia de Alimentos. Editora científica, 386-400.

Souza, M. L. R., Viegas, E. M. M., Kronka, S. N., Amaral, L. A., Parisi, G., Coradini, M. F., \& Goes, E. S. R. (2020c). Cold and hot smoked nile tilapia fillets: quality and yield of pigmented and unpigmented fillets. Italian Journal of Food Science, 32(2). 